American Medical Journal 3 (1): 1-7, 2012

ISSN 1949-0070

C 2012 Science Publications

\title{
Cultural and Nutritional Perspective of Indian Hunter-Gatherers (Kurichia Tribe)
}

\author{
${ }^{1}$ Satyavathi, R.B. \\ ${ }^{2}$ R.K. Anuradha, ${ }^{3}$ K.K. Reddy and ${ }^{4}$ R.B. Singh \\ ${ }^{1}$ Department of Adult and Continuing Education, \\ ${ }^{2}$ Department of Home Science, \\ ${ }^{3}$ Department of Anthropology, \\ Sri Venkateswara University, Tirupati-517 502 andhra Pradesh, India \\ ${ }^{4}$ Halberg Hospital and Research Institute, Civil Lines, Moradabad-10 (UP), India
}

\begin{abstract}
Problem statement: To study the cultural and nutritional perspective of Indian huntergatherers (Kurichia tribe), Kerala, India. Approach: Descriptive and case study analysis. Results: Though Indian scriptures provided a full zodiacal life cycle of one hundred and twenty years for an individual, this goal is rarely reached. However, it is significant to note that in Indian hunter-gatherers (Kurichia tribe) of Kerala State, all the nearest kith and kin of the centenarians successfully lead their life beyond 100 years. They have not suffered from any specific disease in their life time. Though they seem to be weak and fragile, they are sound in health. They led an active life, sometimes walking long distance in their earlier years. However, a major drawback noticed among them was that their vision was affected and some were unable to walk. They were suffering not because of their mental or physical ailments, but worried about the younger generation which is losing faith in their culture under the impact of acculturation process causing intra-generation gap in all walks of life. They felt that this transition would negatively affect the overall community. With regard to lineage of the family, it was noticed that atleast one parent or grandparent or siblings had lived over 90 years. Longevity appeared to be hereditary. There were more women than men. Most of the centenarians were without their spouses. None of them belonged to poor economic status. Most of them had good domestic relationships. Further, the results of the present study revealed that the determining factors of longevity across cultures were almost same, though the nature of some of the variables was culture-specific. Conclusion: Though continued biological and psychological health was a sin quo non for longevity, all variables played a relatively interactive, determining and dynamic role in the process of longevity.
\end{abstract}

Key words: Elderly, acculturation, nutrition, longevity, cultural

\section{INTRODUCTION}

Ageing presents many challenges to society and to individuals. Time has come to think about the ageing process and the needs of older people. A global demographic revolution is underway, witnessing an unprecedented transition from a state of high birth and death rate to one characterized by low fertility and mortality. This transition, which began with the so called developed countries at the end of last century, is now being seen throughout the world. In 1950, there were about 200 million people over 60 years and the old throughout the world reached 550 million by 2000 and by 2025 there will be about 1.2 billion.

With gradual and sustained increase in life expectancy, the number of elderly, both relative and absolute, are increasing all over the world and with this increase is emerging newer needs of this group, which are being felt in all sectors of human sustenance, be it health, social or economic. The elderly population of India rose from $5.5 \%$ of general population in 1950$6.5 \%$ in 1991 and is expected to be $7.7 \%$ by 2001 . Thus, it is important to recognize that ageing is not confined to the developed world. At present majority of the worlds older people $(61 \%)$ live in developing countries, a proportion that will increase to nearly $70 \%$ by 2025 . In other words, one out of every seven elderly would be from India by 2001.

The above statistical description shows that growth rate of elderly population in terms of absolute number and proportion is faster, which is a great challenge to the health service systems. Despite consistent increase

Corresponding Author: Reddy, K.K., Department of Anthropology, Sri Venkateswara University,

Tiruapti- 517502 Andhra Pradesh, India 
in life expectancy it would be wrong to presume that this increased life is healthy and is free from morbidity or disability. In fact, morbidity in elderly segmentis quiet high. Though overall morbidity is changing in the Asian community especially among Indian ethnicity, it is interesting to observe Indian hunter-gatherers (Kurichia tribe) of Kerala, who enjoy a lengthy period of longevity relatively free from age-associated chronic problems, though the life style pattern of this tribal population is changing drastically due to their interaction with industrial population.

The Indian hunter-gatherers (Kurichia tribe) of Wayanad plateau, inhabiting the trijunction of Kerala, Karnataka and Tamilnadu, are a unique tribal community in South India. They are known for matriliny who live in enormous joint families and follow a commune type of family organisation. The elderly Indian hunter-gatherers (Kurichia tribe) constitute about $12 \%$ in their general population. Their size is significantly more compared to the elderly population $(7.5 \%)$ of Kerala state and to the national level $(6.5 \%)$ of India. The proportion of elderly Indian hunter-gatherers (Kurichia tribe) is almost closer to that of many developed countries. Centenarians are common among them. The present study is aimed at focusing on the emic or intracultural perception of centenarians among the Indian hunter-gatherers (Kurichia tribe). In this context, the following ethnographic account of Indian hunter-gatherers (Kurichia tribe) throws light for a comprehensive sociocultural perspective of centenarian Kurichias.

Family setting: The Indian hunter-gatherers (Kurichia tribe) live in scattered home-steads on leveled grounds adjacent to their agricultural fields and the distance between one such settlement to another may range from 2-10 km. Their massive joint families maintain a matrilineal heritage, which can be understood in several aspects such as leadership and its succession, property inheritance, management of the family on an egalitarian basis, first name of the family members and rites-depassage. With the passage of time, the joint family system and matriliny have started facing threat due to the impact of social changes occurring around them, particularly in the areas closer to urban centres and hence, nuclear families are slowly emerging and adopting patrilineage. However, the rural and land owning Indian hunter-gatherers (Kurichia tribe) strictly adhere to their culture following matrilineage.

The older generation also continues to have the leadership control over the family. But modern education and imitation of the neighbouring communities make the present day youth prefer nuclear families and patrilinial system. Consequently, older generation is losing control over the family and subjected to unpredicted stress. However, senior most of the family member (locally called "Pittan") is given much importance in all walks of life. Even after retiring from head-manship, the senior member enjoys utmost respect and have a say in domestic affairs. When the headman exhibits favouritism for his children neglecting his kith and kin in the joint families other members silently bear the brunt of agony, as the Kurichias' intracultural perception of communication between the young and the old prohibits the humiliating treatment of the elders.

In case of absence of head-man for many days, he has to nominate other senior member or suitable person to execute the things on his behalf. Headman is entitled for collective ownership rights. He plays central role in income generation and distribute it evenly. The Kurichia family has a common kitchen and all the members of the family have to dine under one roof. But there are some joint families, where houses are distributed here and there with separate kitchen, but the role of head-man remains the same, like his counterparts, for all practical purposes. Property inheritance is based on matriliny. On account of the matrilineal system the Kurichia women enjoy an enviable position. Widows in particular have much security and face no discrimination.

Usually the elderly maintain social distance with the strangers or other caste groups, assuming that they will be polluted during their encounter with outsiders. The women folk take bath immediately after a short meeting with others. During menstrual period, ladies are kept in a separate hut for a week, not allowing even her children and husband to touch. The oldest lady of the family called Muthachi enjoys all privileges and facilities. Gender based harassment of any kind, including sexual abuse, is not noticed in the huntergatherers (Kurichia tribe) community. Further, the world-view of hunter-gatherers (Kurichia tribe) is known for their sense of equality within their community. In spite of class differences Kurichias do not evince any differentiation in day-to-day life. In fact, there is no beggary in the community. However, hunter-gatherers (Kurichia tribe), like the other surrounding communities, are under rapid social changes. The younger generation is continuously under stress to get away from their own traditions in imitation of other modern communities.

Food and health: The elderly hunter-gatherers (Kurichia tribe) are fortunate enough to live upto 80 or 100 years or more enjoying sound health. It is significant to note that during the field work, the older 
Kurichia seem to be more active and healthy than the youngsters. This phenomenon is attributed to the culture of Kurichias which the younger generation often dislikes. The general longevity and overall health of the Kurichia also depend upon taking of healthy foods like raagi and meat (forest based) as staple foods coupled with the regular intake of green leafy vegetables and tubers. One centenarian Mr. Chandu aged about 101 years commented that "I have never used any purchased food product from the market other than salt in my life time and never traveled in any vehicle fearing that my touch with outsiders pollutes me". Even now the elderly generation prefers to take cultivated food and hunted meat. But, in course of time, meat intake of the Kurichias is drastically reduced due to the ban imposed by theForest Department. Paddy cultivation has been decreasing and raising of commercial crops is intensified which has resulted in the scarcity of brown rice. Chemical fertilizers and pesticides are widely used.

Availability of green leaves and tubers has also lessened. Elderly population is most unhappy with this transition, though the latter is happy for younger generation. Reacting to this Mr. Chandu points out "my father and grandparents lived happier than I am. These changes will destroy our community. I am very unhappy to notice that the youngsters do not want to consume forest products which are the hidden secret of our health and longevity. The indigenous knowledge system will be buried with me". Working Environment of hunter-gatherers (Kurichia tribe) possess strong physique. Though they are agriculturists, they are fond of hunting (though it is banned). The work environment of Kurichias is located in the midst of two hills. Both men and women and grown up children participate in various tasks of cultivation. They usually walk for many miles every day which provides essential exercise. Consequently, obesity or overweight is not noticed among them (Reddy et al., 1999). The work load is distributed among them as per the advice of headman. Dissatisfaction and stress are often noticed among the family members regarding sharing of the work. However, such phenomena are not openly discussed out of respect for the elderly.

Ecology: The excellent ecology is also another factor for the longevity of the hunter-gatherers (Kurichia tribe) inhabiting Wayanad region of Kerala. The climate is also pleasant with good rainfall. Even now Wayanad region receives maximum rainfall in the State of Kerala. But Kurichia elder generation laments by stating that "in our early days, we used to receive three spells of rainfall per month, now see, we are not receiving the same amount of rainfall because of forest depletion. Allintruders are destroying our climate, environment, health and traditions". Collective
Ownership of Land Ownership of land is collective among the Kurichias, which facilitates them to lead a less expensive life. They are not ambitious in the accumulation of undesirable wealth. However, younger Kurichias are more ambitious in earning money and crazy after modern life which is resulting in stress and indebtedness. Many older people exhibited their anxiety over the ambitious paths of the youngsters vis-a-vis their stress. This transition is slowly resulting in economic insecurity in the younger generations. Presence of Centenarians in Kurichia Community. As stated earlier, the proportion of elderly hunter-gatherers (Kurichia tribe) is closer to that of many developed countries. A few case studies are presented below for a comprehensive understanding of centenarian life-styles

Case 1: Mr. N. C. Chandu, aged 101 belongs to Makkachira Taravad (Joint family) of Tirunelly Panchayat of Wayanad which consists of 60 members spreading four generations. It is reported that Mr. Chandu's forefathers also had such a lengthy longevity. Mr. Chandu is the eldest one followed by 10 siblings (four brothers and 6 sisters). All of them are alive and live in different joint families. $\mathrm{He}$ is the only centenarian in the Karichal Taravad. No specific disease is complained of either by Mr. Chandu or his siblings. In fact, they are not aware of the concept of disease; they also never sought any medical help. His work culture and food habits are different from those of the people of present generation. Since his early childhood he involved himself in cultivation and hunting. He prefers to take food material that is drawn from the forest and his own fields. He never traveled by bus or any other means of transport with the fear of getting polluted with the touch of others. Even during our interview he maintained some distance. He is highly ethno-centric and is very much attached to his culture. $\mathrm{He}$ also wept at the time of interview by mentioning that the present youth are negatively affected by the imitation of external culture and losing their health and are also addicted to many bad habits like alcoholism. He never smoked and consumed alcohol in his life time. However, he is fond of chewing betel leaf and nut powder. He is not over-ambitious in life and he has no tensions. He is now able to walk with the help of a stick.

Case 2: Mrs. Ammani, aged about 100 years, belongs to Olancherry Taravad. She is a widow and her husband died at the age of 103. She lives with her elder daughter and her children. She belongs to a small joint family consisting of 15 members. She has five sisters and two brothers. All of them died at the ages around 90's. She has four sons and three daughters. She cannot walk and 
stand. Her vision is poor. She has no specific complaints about her health except vision problem. Her siblings did not die of any specific disease but with the advancement of age. She is happy with her present condition and surviving by recollecting memories about her family members and by playing with the children. She is often found to be a good asset to the youngsters as she reveals many things about their ancestors, their might and valor in historicity and purity in relation to other communities. Regarding the work culture, from her early childhood she involved herself in various agricultural tasks and in looking after the family. She prefers to take food material that is drawn from the forest and her own fields. Though her digestion power is drastically affected but she is still fond of taking her own indigenous food. She is fond of chewing betel leaf and nut powder and her positive attitude in life is tuned to enculturising and looking after young children. She has no exposure to the outer world. When she was requested through her grandson to pose for a photograph, she started weeping stating that she was posing for a photograph for the first time and disclosed that posing for a photograph pollutes her apart from decreasing her longevity. When she was asked to reveal her age at menarche, she felt very shy and laughed merrily. After consoling she was interviewed about her life styles and health. She has no specific health complaint except her inability to walk and see. She mentioned that her mother and some of their own family members were hale and healthy even at their centenary year. But she laments that she was not so healthy when compared to her immediate ancestors. Though she gave birth to seven babies, she continuously worked in her paddy fields until 80s. She claims that indigenous food and culture alone contribute for their long and healthy life. She believes that taking Cassia Tora, brown rice, raagi and meat and other forest products are the secret of the Kurichia longevity. The respect she enjoys in her household also helps her lead a tension-free life.

Case 3: Mr. Raman, aged 101 years, hails from Tatchaerakolli Taravad. He lives with his elder daughter and her children. This joint family consists of 45 members. He has two sisters and three brothers, all of them are alive except his immediate sister who died at the age of 93. Raman has five sons and three daughters. He can seldom stand with the help of stick and cannot walk. He has no specific complaints about his health except poor vision. He is happy with his life but often feels sorry for the inability to walk and to do the daily chorus on his own. Since his early childhood Raman participated in different agricultural operations. He prefers to take food material that is drawn from the forest and his own fields. He never smoked and consumed alcohol but is fond of chewing betel leaf and nut powder and he now derives his contentment in guiding and looking after young children. Further, Raman has good understanding of the intricacies of market and he takes all precautionary measures while disposing his yield. He takes bath immediately after returning from the market and prays to god regularly. He claims that his food habits and traditional style of living contribute to longevity. He is very fond of hunting. Narrating his childhood experiences, Raman recollects that he used to roam about in the forest for kilometres and often he would take shelter in the deep forests itself and only returned home after three or four days. He was guided by his elders about the usage of many forest products that have medicinal value. He also claims that he is familiar with much of the forest wealth which he can use for the well-being of his fellowmen, but he laments that the present youth are not interested in knowing and making use of the forestbased wealth, as they have to travel longer distances in the forest and because of their exposure to the modern medicine, they lost interest in the traditional medical lore. Further, Raman also feels that there is no one to guide the youth after his demise.

Case 4: Another centenarian, Mrs. Ammani belongs to Arikera Taravad. She is a widow. Her husband died when she was 92. She lives with her elder son and children. She belongs to a joint family consisting of 32 members. She has three elder sisters and three elder brothers. Her two brothers and one sister died after completing centenarian life. Ammani has four sons and three daughters. One of her sons is an allopathic doctor. She can neither walk nor stand. Her vision is also poor. But, she has no specific complaints about her health. Her siblings also did not die of any specific disease but with the advancement of age. She is happy with her present life and livelihood and in looking after the young kids. Since her early childhood she involved herself in agricultural pursuits and in maintaining the family. She prefers to take food material that is procured from the forest and her own fields. She is fond of chewing betel leaf and nut powder and she likes to look after young children. She is highly ethnocentric about the Kurichia traditions and customs. After a brief interview with the researchers she asked her daughter-in-law to take her to the bathroom in order to become pollution free. She also attributes her natural physical disability to the acculturation process that is taking place in her community and she is very much worried about this transition.

\section{Determinants of longevity: an analysis:}

Methods: The present study was carried out on the basis of a review of studies on centenarians (Kinzel et 
al., 1990; Poon et al., 1992; Macigilian et al., 1993; Kumar, 1996; Abikusno, 2002) and on the Indian Hunter-Gatherers (Kurichias) (Ramachandran, 2004). This exercise enabled the researchers to pickup several relevant variables that are likely to contribute for longevity. To these were added a few other variables that complement for the longevity of the tribals in Indian context. They were categorised as (1) Demographic details (2) Family history (3) Disability (4) Nutrition (5) Stress and coping styles (6) Temperament (7) Communication (8) Cognition (9) Life style (10) Social support system and family interaction. Further, the socio-cultural and operation research (SCOR) technique was used in the present study.

Based on age, gender and socio-economic status several informants were informally interviewed. The researchers met the respondents, repeatedly in order to know their intracultural perspective and discussed local ethnography, which, consisted of family setting, kinship, inheritance, collective ownership of land, working environment, economy, food and health, social security and world-view. Discussion matrix of these, thus, provided a guide or list of important items of analysis in terms of the socio-cultural perspectives of the centenarians.

Further, the researchers identified the centenarians in the Kurichia settlements and their ages as per the electoral rolls and supplemented by the information from the centenarians and their families. It was crosschecked with major historical or geographical events. From these the lowest probable age was taken as the age of the centenarians and a few detailed case studies were recorded with the help of the schedule of the questions and probes.

Analysis: Satamanam Bhavati. (May you live for a hundred years) is a blessing showered on the young, reflecting an age old tradition in India. Though Indian scriptures provided for a full zodiacal life cycle of one hundred and twenty years for an individual, this goal is rarely reached. However, it is significant to note that in the Indian hunter-gatherers (Kurichia tribe) all the nearest kith and kin of the centenarians successfully lead their life beyond 100 years. They have not suffered from any specific disease in their life time. Though they seem to be weak and fragile, they are sound in health. They had led an active life, sometimes walking long distance in their earlier years. However, a major drawback noticed among them was that their vision was affected and some were unable to walk. They were suffering not because of their mental or physical ailments, but worried about the younger generation which is losing faith in their culture and under the impact of acculturation process causing intra-generation gap in all walks of life. They felt that this transition would negativelyaffect the overall Kurichia community. However, regarding social interactions they felt happy for being respectedand heard. Yet the younger generations often expressed their dissatisfaction in their traditional life-style and always wanted freedom in their social life. This would affect not only their culture but their health too in many ways.

Nutritional history showed that all the centenarians were non-vegetarians, choosing from different food sources. They rarely took medicines from doctors, mostly meeting their requirements from tribal medicine. Nobody was habituated to alcohol or smoking but several of them chewed betel leaves. They were also interested in keeping good health and following healthy and hygienic practices of food. With regard to lineage of the family also, it was noticed that atleast one parent or grandparent or siblings had lived over 90 years. Longevity appeared to be hereditary character. There were more women than men. Most of the male or female centenarians were without their spouses. None of them belonged to very poor or poor economic status. Most of them had good domestic relationships. Causes of deaths among Kurichias are mainly fall, bites, drowning and killing during hunting or other natural calamities. Cancer, heart attack, hypertension, obesity and diabetes mellitus are uncommon among Kurichia hunter-gatherers (Singh et al., 2011a).

Food intakes among indian hunter-gatherers (Kurichia): The food consumption pattern of the hunter-gatherers (Kurichia tribe) has some similarity with the food consumed by other hunter-gatherers (Loomis, 1967; Lee, 1968; Singh et al., 2010); vegetables, leaves, nuts, tubers, fruits, whole grains, eggs, fish, honey. Indian Kurichia hunter-gatherers are known to be non-vegetarians. Meat is taken mostly from the untamed animals and the time of hunting was possibly, early in the morning, at sun rise when animals come for drinking of water at the river banks. They are fond of taking fresh meat that is hunted by themselves for consumption. Since the government of India has imposed ban on hunting in the forest, their meat intake is now drastically reduced. Dietary intakes assessed by 3-days dietary recall, were recorded in a questionnaire, by the dietitian and by asking food intake frequency in the last one month. Food models, food measures and food portions were showed to individuals with the help of an educated Kurichia, who knew both the languages, during dietary assessments.

The dishes taken by Indian hunter-gatherers (Kurichia tribe) will predominantly occupy with green leaves like Cassia tora, Alternanthera sessilis, vegetable like hydrocotyle, clerodendron, nymphaea nouchali and 
roots like ceropegia and elaeocarpus (Reddy et al., 1999; Reddy et al., 2006). In fact, sugar is a recent addition during the last 50 years. The main foods are; brown rice, seasonal green leaves and fruits, roots and tubers, fish and butter milk. Alcohol and tobacco intakes are considered evils which are uncommon. These foods are rich sources of w-3 fatty acids, antioxidants, essential amino acids, vitamins and minerals and soluble fiber and are low in saturated fat, w-6 fat and trans fat. Sugar is the only refined carbohydrate. The food and nutrient intakes among hunter-gatherers (Kurichia tribe) appear to have similarity with the food advised in the ancient scriptures classically known as Rajasik diet.

Man appears to live in a nutritional environment which completely differs from that for which our genetic constitution was selected. During the last 100160 years, dietary intakes have changed significantly, causing increased intake of Saturated Fatty Acids (SFA), trans fatty acids and linoleic acid and decrease in w-3 fatty acids, from grain fed cattle, tamed at farm houses, rather than meat from running animals. In general, there is increase in the intake of refined carbohydrates and decrease in the intake of complex carbohydrates, essential amino acids, minerals, vitamins and antioxidants. In the present era, a marked reduction in consumption of w-3 fatty acids, antioxidants, vitamins and minerals and proteins and significant increase in the intakes of carbohydrates, (mainly refined,), fat (saturated, trans fat, linoleic acid) and salt was documented when compared to Paleolithic period (Eaton et al., 1998; Meester, 2007; 2009; Eaton, 2009; Singh et al., 2011b). These dietary changes in conjunction with sedentary behavior, mental strain, pollution, tobacco consumption and alcoholism, particularly after 1910, during the last 100 years may have caused damage to our genes, leading to emergence of non-communicable diseases. The protective effects of Paleolithic diets in the form of Mediterranean diet, Indo-Mediterranean diet, Japanese diet and DASH diet have been documented in the several previous studies (Fung et al., 2008; Katcher et al., 2008; Trichopoulou et al., 2009). The traditional concepts of nutrition, particularly, Rajasic diet and the foods consumed by Indian hunter-gatherers also support the consumption of natural foods, similar to these diets. These studies have clearly demonstrated the beneficial impacts of these diets, against coronary artery disease, hypertension, type 2 diabetes mellitus and cancers.

Further, the results of the present study revealed that the determining factors of longevity across cultures were almost same, though the nature of some of the variables was culture-specific. Though continued biological and psychological health was a sin quo non for longevity, all variables played a relatively interactive, determining and dynamic role in the process of longevity. In view of this, there is an urgent need to study other neighbouring tribal communities of Kurichia hunter-gatherers in particular and Indian tribals in general for comparing and collating the information to deduce commonalties and locate differences regarding the determinants of longevity.

\section{ACKNOWLEDGEMENT}

Dr. K.K. Reddy greatly appreciate the financial assistance provided by the Indian Council of Medical Research, New Delhi, India. This work has no conflict of interest.

\section{REFERENCES}

Abikusno, N., 2002. Sociocultural aspects of the aged: A case study in Indonesia. Asia. Pacific. J. Clin. Nutr., 11: S348-S350. DOI: 10.1046/j.14406047.11.s1.1.x

Eaton, S.B., 2009. Evolution and Cholesterol. In: A Balanced Omega-6/Omega-3 Fatty Acid Ratio, Cholesterol and Coronary Heart Disease, Simopoulos, A.P. and F.D. Meester, (Eds.). Karger Publishers, New York, ISBN-10: 3805592248, pp: 46-54.

Eaton, S.B., S.B. Eaton., A.J. Sinclair., L. Cordain and N.J. Mann, 1998. Dietary intake of long-chain polyunsaturated fatty acids during the paleolithic. World Rev. Nutr. Diet., 83: 12-23. PMID: 9648501

Fung, T.T., S.E. Chiuve, M.L. McCullough, K.M. Rexrode and G. Logroscino et al., 2008. Adherence to a DASH-style diet and risk of coronary heart disease and stroke in women. Arch. Int. Med., 168: 713-720.

Katcher, H.I., R.S. Legro, A.R. Kunselman, P.J Gillies and L.M Demers, et al., 2008. The effects of a whole grain-enriched hypocaloric diet on cardiovascular disease risk factors in men and women with metabolic syndrome. Am. J. Clin. Nutr., 87: 79-90.

Kinzel, T., D. Wekstein and C. Kirkpatrick, 1986. A social and clinical evaluation of centenarians. Exp. Aging. Res., 12: 173-176. PMID: 3830238

Kumar, V., 1996. Aging: Indian Perspective and Global Scenario. 1st Edn., Institute of Medical Sciences, New Delhi, India, pp: 474.

Lee, R.B., 1968. What Hunters do for a Living: A Comparative Study. In: Man the Hunter, Lee, R.B. and I. Devore, (Eds.). Transaction Publishers, New York, ISBN-10: 020233032X, pp: 41-48. 
Loomis, W.F., 1967. Skin-Pigment Regulation of Vitamin-D Biosynthesis in Man. Sci., 157: 501506. DOI: $10.1126 /$ science.157.3788.501

Macigilian, F.B., C. Campana, F. Ettorre and E. Capponi et al., 1993. Health status in Italian centenarians. Proceedings of the 15th International Congress of Gerontology, (ICG' 93), Budapest, Hungary, pp: 78-78.

Meester, F.D., 2007. Wild-Type Land Based Foods in Health Promotion and Disease Prevention: The LDL-CC:HDL-CC model. In: Wild-Type Food in Health Promotion and Disease Prevention: The Columbus Concept, Meester, F.D. and R.R. Watson, (Eds.). Humana Press, ISBN-10: 1588296687, Totowa, N.J., pp: 3-20.

Meester, F.D., 2009. Progress in lipid nutrition: The columbus concept addressing chronic diseases. World. Rev. Nutr. Diet., 100: 110-121.

Poon, L.W., G.M. Clayton, P. Martin, M.A. Johnson and B.C. Courtenay et al., 1992. The Georgia Centenarian Study. New York; Baywood Publishing Co, 34: 1-17.

Ramachandran, B., 2004. Ecological references in the folksongs of Kurichian tribe of Kerala. Indian Folklore. Res. J., 1: 3-3.
Reddy, K.K., A.P. Rao and T.P. Reddy, 1999. Serum vitamins E, A and lipid peroxidation levels in Kurichias, an Indian tribal population. Indian J. Biochem. Biophys., 36: 44-50. PMID: 10549160

Reddy, K.K., T.P.K. Reddy, B.K. Reddy, A. Papa Rao and R.B. Singh, 2006. A socio-cultural perspective of centenarians in a tribal community of South India. Res. And. Dev. J., 12: 30-36.

Singh, R.B., F. DeMeester and A. Wilczynska, 2010. The tsim tsoum approaches for prevention of cardiovascular disease. Cardiology. Res. Practice., 2010: 18-18. DOI: 10.4061/2010/824938

Singh, R.B., K.K. Reddy, J. Fedacko, F.D. Meester and A. Wilczynska et al., 2011a. Ancient Concepts of Nutrition and the Diet in Hunter-gatherers. Open. Nutr. J., 4: 130-135.

Singh, R.B., M. Moshiri, F. DeMeester, L. Juneja and V. Muthusamy, 2011. The evolution of low w-6/w3 ratio dietary pattern and risk of cardiovascular disease and diabetes mellitus. Nova Science Publishers.

Trichopoulou, A., C. Bamia and D. Trichopoulos, 2009. Anatomy of health effects of Mediterranean diet: Greek EPIC prospective cohort study. Greek epic prospective heart study. B.M.J., 338: 1-18. DOI: 10.1136/bmj.b2337 